\title{
Práticas cotidianas do recreio escolar. táticas de quem gosta de inventar
}

The daily practices school break: tactics who you like to invent

\author{
1 Marcelo Paraiso Alves marcelo.alves@ifrj.edu.br \\ 2 Isabela Carvalho Rabelo \\ 2 Rosinei Maria de Oliveira Tuler \\ 2 Maria Conceição Vinciprova Fonseca
}

\begin{abstract}
Resumo
A pesquisa se configura a partir de uma pesquisa de campo que explicita a interação dos discentes, o espaço do recreio e a escola. 0 objetivo foi investigar as práticas socioculturais dos alunos durante o recreio escolar. Considerando que a escola é uma instituição que busca normatizar o espaçotempo dos sujeitos que se encontram sob a sua ação, cabe refletir: será que o recreio escolar é utilizado como um espaço de criação e reinvenção de possibilidades de movimentos? Como opção metodológica nos aproximamos da etnografia para o aprofundamento nas práticas cotidianas durante o recreio escolar, de modo a nos inteirarmos sobre as diferentes relações existentes entre os sujeitos e sobre as diferentes ações praticadas por eles. Os resultados revelam que, embora o recreio seja um espaço controlado pela escola, ainda é concebido pelos alunos como um local favorável a diversas descobertas, portanto, aberto a possíveis problematizações e reinvenções culturais.
\end{abstract}

\section{Palavras-chave}

Cotidiano; ensino fundamental; táticas; recreio.

\begin{abstract}
The study is from a lookup field that explains the interaction of students, recreational space and the school. The objective was to investigate the sociocultural practices of students during recess at school. Where as the school is an institution that seeks to standardize the space-time of the subjects that are under your action, fits reflect: does the school playground isused as a space for creation and reinvention of possibilities of movement? As we approach them ethodological option Ethnography to the deepening in the daily practices of the school during recess, in order to find us on the different relationships between the subject and the different actions carried out by them. The results show that, although the playground is an area controlled by the school, is still designed by students as a hospitable home to various findings, therefore, open to possible problematizações and reinventions.
\end{abstract}

\section{Keywords:}

Daily life; Elementary School; Tactics; Playground.

\section{Como você deve citar?}

ALVES, Marcelo Paraiso et al. Práticas cotidianas do recreio escolar: táticas de quem gosta de inventar. Cadernos UniFOA, Volta Redonda, n. 35, p. 75-86, dez. 2017. 


\section{INTRODUÇÃO}

O presente estudo trata da questão da apreensão do espaço do recreio escolar pelos alunos dos anos iniciais do Ensino Fundamental de uma escola pública localizada no município de Rio Claro-RJ.

O debate se apoia sobre uma pesquisa de campo que explicita a interação dos sujeitos entre si, o espaço do recreio escolar, docentes, direção e funcionários da referida instituição. 0 objetivo foi investigar as práticas socioculturais dos alunos durante o recreio escolar, por considerar que, nesse espaço, os alunos produzem ações singulares que indicam o modo como se apropriam da escola e do mundo, da mesma forma em que a referida instituição escolar oferece estratégias de uso do espaço.

Para Neuenfeld (2008, p. 37) "é preocupante o modo como esse espaço de tempo está sendo utilizado pelas crianças. Em face de um lazer de mercado" que determina as ações que as crianças devem desenvolver.

Wenetz, Stigger e Meyer (2013, p. 117), ao pesquisar o recreio escolar, mencionam que "a escola marca seu próprio som, seu próprio ritmo, regulariza, delimita a entrada e a saída, a hora de fazer fila".

Nessa linha de pensamento, a escola é uma instituição que busca normatizar os espaços e o tempo dos sujeitos que se encontram sob a sua tutela, e que, em muitos momentos, disciplina os educandos que se encontram vivendo tal cotidiano. Assim, cabe refletir se o recreio escolar escapa ou rompe com essa lógica. Diante do exposto, a questão central deste estudo emerge das seguintes questões: será que o recreio escolar vem sendo realmente utilizado como um espaço de criação e reinvenção de possibilidades de movimentos? Até que ponto o controle da escola sobre o corpo pode ser percebido nesse espaço?

Entendendo que, embora o recreio escolar seja um espaço controlado pela escola, ainda o percebemos como um local favorável a diversas descobertas, portanto, aberto a possíveis problematizações. Dessa forma, decidimos investigar o recreio como um local de construção coletiva, na intenção de romper com a percepção de improdutividade que emerge desse espaço, discutindo a relevância deste para a área da Educação Física Escolar e para áreas afins (ALVES; PRETTO, 2008; CAMPOS; COSTA, 2014).

\section{MERGULHO NO COTIDIANO DO RECREIO ESCOLAR: PROCEDIMENTOS TEÓRICOS E METODOLÓGICOS}

Diversas pesquisas sobre diferentes assuntos vêm sendo realizadas por inúmeros pesquisadores que buscam compreender um pouco mais sobre o que é produzido pelos sujeitos ordinários nos múltiplos cotidianos em que habitamos (CERTEAU, 2009).

Não podemos traduzir a vida cotidiana por meio de explicações generalizadas a respeito de sua dinâmica e escorregadia riqueza. "Organizar e traduzir em linguagem compreensível o que nela ocorre tem sido um desafio para pesquisadores e estudiosos das mais diversas áreas" (OLIVEIRA, 2001, p.40).

Para a autora, esse espaço de ações e relações entre os seres humanos pode trazer, em seus detalhes minuciosos, uma rica fonte de fenômenos que nos possibilitará mergulhar na intenção de descobrirmos as belezas e as emoções desse complexo objeto de estudo (o cotidiano), que, por algum momento, poderíamos ter pensado nem existir. 
Portanto, não basta apenas enxergarmos o cotidiano como aquilo que se passa, acontece ou o que se toca. Devemos buscar aquilo que nos passa, nos acontece e que nos toca. Nesse ato de pesquisar, a vivência se aproxima da experiência mencionada por Larrosa (2002), visto que, para o autor, a experiência é aquilo que nos toca, por isso essa ótica de investigação trabalha com a ideia de pesquisa e formação continuada: "essa indissociabilidade tem sido compreendida e defendida como constitutiva do trabalho docente universitário do professor que pesquisa e ensina-forma, embora sejam esporádicas experiências desse tipo na formação inicial" (DE CASTRO LIMA; GERALDI; GERALDI, 2015, pp. 27-28).

Seguindo o caminho traçado por De Castro Lima, Geraldi e Geraldi (2015), neste estudo, a narrativa emerge como um método de pesquisa, pois decorre das experiências dos pesquisadores que tomam para si o objeto pesquisado como uma forma de compreensão, rompendo com o caráter experimental das pesquisas modernas, para propor um mergulho vivencial (ALVES, 2003; FERRAÇO, 2007). Tal intenção parte "da insatisfação com as produções no campo da educação que se caracterizaram por falar sobre a escola em vez de falar com ela e a partir dela" (DE CASTRO LIMA, GERALDI; GERALDI, 2015, p.2).

Portanto, este estudo opta por se aproximar da pesquisa na perspectiva de De Castro Lima, Geraldi e Geraldi (2015), que concebe a narrativa a partir das experiências do vivido. Para os autores, essa perspectiva existe, aproximadamente, há duas décadas, tendo como seu precursor o estudioso Nóvoa (1997) e suas pesquisas que nos remetem às histórias de vida de professores.

Assim, esta pesquisa buscou, na perspectiva etnográfica (GEERTZ, 2013), o referencial para o aprofundamento nas práticas cotidianas dos alunos durante o recreio escolar, de modo a nos inteirarmos sobre as diferentes relações existentes entre os sujeitos pesquisados e também sobre as diferentes ações praticadas por eles.

Para Geertz (2013), o homem é um ser que está amarrado nas teias de significados que ele mesmo teceu em sua relação com o seu contexto, portanto, ao investigá-lo, não buscamos, como na ciência experimental (laboratorial) a partir das leis científicas, comprovar algo, mas procuramos, à maneira de uma ciência interpretativa, procurar significados para compreender os modelos de ação em que os sujeitos estão imersos: "é justamente uma explicação que eu procuro, ao consumir expressões sociais enigmáticas na sua superfície" (GEERTZ, 2013, p. 4).

Outro autor que nos acompanhou neste estudo foi Pais (2003). Ele menciona que, ao considerar a sociologia do cotidiano e o modo como o pesquisador, a partir de sua subjetividade, se apropria da realidade para desenvolver suas discussões, é preciso romper com o paradigma moderno. Tal ruptura nos leva a compreender que o pesquisador não coleta dados como se entrasse em um supermercado e capturasse os produtos, mas os produz ao seu modo, a partir de sua concepção de mundo e sua cultura.

Nesse sentido, para a produção de dados (PAIS, 2003) deste estudo, privilegiaremos a descrição densa e de segunda mão, conforme proposto por Geertz (2013), a fim de mergulharmos de forma mais intensa no cotidiano desses praticantes, por meio da utilização de um diário de campo, na intenção de apreender as impressões por eles geradas em sua relação com o mundo vivido. Para o autor, apenas o nativo é capaz de realizar uma interpretação em primeira mão.

Portanto, cabe ressaltar que o trabalho em questão está fundado nos estudos do cotidiano e tem como espaço de análise o recreio escolar dos anos iniciais do Ensino Fundamental da Escola Municipalizada Aureliano Portugal, situada no distrito do município de Rio Claro-RJ.

A instituição referida está localizada em uma área rural e conta atualmente com, aproximadamente, 280 alunos de classe popular, oferecendo atendimento nas modalidades de Educação Infantil, 
Ensino Fundamental, Educação de Jovens e Adultos (EJA) e Atendimento Educacional Especializado (AEE) para pessoas com necessidades educativas especiais, no contraturno da aula regular.

A presente pesquisa se restringiu à observação do recreio dos anos iniciais do Ensino Fundamental, composto por alunos com idade entre 5 e 10 anos, utilizando como instrumento de pesquisa um diário de campo. 0 mergulho no cotidiano (ALVES, 2003) aconteceu em dois dias da semana, quintas e sextas-feiras, no período vespertino, compreendendo intervalos de vinte minutos. Salienta-se que esta pesquisa foi aprovada pelo Comitê de Ética em Pesquisa em Seres Humanos do UniFOA, sob o número 46482415.4.0000.5237.

\section{LUGAR OU ESPAÇO: COMO SE CONFIGURA O RECREIO ESCOLAR?}

Segundo Neuenfeld (2008), a palavra recreio se origina do termo recrear, que significa prazer, divertimento. Portanto, podemos entender o recreio como o momento na escola ou período entre aulas destinado à recreação e ao desenvolvimento de diversas práticas corporais.

Cruz e Carvalho (2006, p. 115) dizem que o recreio escolar é um "espaço que, embora esteja determinado pelas relações institucionais em que está inserido, possui relativa autonomia do mundo adulto".

Para Matos (2015), o espaço do recreio é favorável tanto para o desenvolvimento motor quanto social, pois esse espaço permite que as crianças troquem experiências, vivam aventuras, vivenciem sentimentos, mostrem suas emoções e selecionem seus amigos.

Já Benvegnú (2012), associa o recreio a um tempo que está inserido dentro de uma rotina diária, como "terapia", descanso do corpo e da mente e que, de certa forma, exige uma participação ativa dos sujeitos.

Assim, no estudo em questão, o recreio escolar será concebido a partir da noção de espaço de Certeau (2009), pois, ao adentrarmos no recreio, nos deparamos com as diversas ações dos alunos, o que nos permitiu constituí-lo como um local de reinvenção e recriação de movimentos e práticas culturais.

Para Certeau (2009, p.202) "o espaço é um lugar praticado". É configurado como um local animado pelo desdobramento de diversos movimentos e, de certo modo, é o resultado das diferentes interações e operações que o levam a funcionar de acordo com situações conflituosas ou de proximidades. Diferente de lugar, o espaço não apresenta a estabilidade nem a univocidade de um próprio. 0 autor busca definir espaço e lugar de modos distintos, pois, para ele, o lugar se configura como um local fixo, engessado, sem movimento, reduzido apenas ao estar no sentido de passividade, diferente da noção de espaço, que abrange as ações dos sujeitos e suas diversas operações.

A partir do momento em que as crianças se apropriam do pátio escolar para a realização de suas ações, este se transforma imediatamente em um espaço que se realiza pelo fato de estar sendo vivenciado pelas diversas dinâmicas dos movimentos que nele ocorrem e o potencializam. $E$, assim, passa instantaneamente da condição de um simples lugar a um lugar praticado (CERTEAU, 2009). A escola, portanto, ou simplesmente o pátio escolar, é transformado em um espaço praticado pelos diversos alunos, que inventam e desenvolvem esse cotidiano por meio de diversas situações.

A "invenção do cotidiano e as artes de fazer", conforme mencionada por Certeau (2009), possibilita uma forma de alteração dos objetos e códigos e assegura que os sujeitos se reapropriem do espaço e de seus usos cada um a sua maneira, procurando se apropriar de tais vivências de acordo com as 
demandas individuais e coletivas. De acordo com o autor, "essas 'maneiras de fazer' constituem as mil práticas pelas quais usuários se reapropriam do espaço organizado pelas técnicas da produção sociocultural" (CERTEAU, 2009, p.41).

No cotidiano escolar, principalmente no recreio, é possível ter a percepção de que os sujeitos ali inseridos lidam constantemente com diferentes artimanhas e até mesmo burlas, na intenção de driblar as complexas situações que se seguem diariamente. Dessa forma, o autor constrói uma discussão acerca de uma distinção existente entre estratégias e táticas.

Para o autor, a estratégia emerge da relaçãode poder como uma forma de domínio dos fortes sobre os fracos, ou seja, uma ideia de poder dominante e influente, no qual a constante busca por intimidação, convencimento e, até mesmo, dominação estão inseridas. Já a tática é a arte do fraco; em contraposição à estratégia, que está vinculada ao poder, a tática é estabelecida pela ausência desse poder (CERTEAU, 2009).

Assim, no cotidiano da escola, foi possível perceber que os sujeitos praticantes que ali se inserem caminham constantemente por esses dois espaços. Algumas vezes, mostram-se detentores do poder e, outras vezes, apresentam simplesmente a ausência dele. E é nessa ausência que os sujeitos criam suas artimanhas para burlar esse poder que se instala nas suas relações e, assim, fazem prevalecer simplesmente as suas vontades momentâneas (SILVA; LíRIO; MARTINS, 2011).

\section{UM PASSEIO PELO ESPAÇO DO RECREIO ESCOLAR...}

O espaço escolar escolhido para pesquisa é delimitado por altos muros e apresenta dois portões para a entrada dos alunos (sendo o menor deles o mais utilizado). Todo esse espaço é dividido em três blocos: o primeiro é constituído pela biblioteca, sala dos professores, secretaria, uma sala de aula, dois banheiros e o refeitório; o segundo conta com um grande pátio, que apresenta na sua parte superior três salas de aulas; e o terceiro abrange mais seis salas de aula e dois banheiros. Além desse pátio, há também um grande espaço descoberto que se une a uma única quadra que, apesar de ser coberta, não contém nenhuma demarcação para a prática de esportes.

É nesse espaço que tivemos a oportunidade de mergulhar para conhecer e compreender o cotidiano dessas crianças e tudo aquilo que elas se propunham a fazer em um curto intervalo de tempo. Não nos bastou apenas observar, pois foi preciso adentrar no mundo desses alunos e saborear cada gesto e movimento que possibilitava a eles o direito de sorrir, mesmo que, em muitos casos, as estratégias da escola estivessem presentes, conforme podemos perceber nos excertos da pesquisa: "quando soava o sinal do recreio, exatamente às $14 \mathrm{~h} 30$, os alunos menores se organizavam em filas e eram conduzidos por suas professoras até o refeitório. Aquelas crianças que corressem e não respeitassem a fila eram advertidas" (EPISÓDIO DO CADERNO DE CAMPO).

Conforme observações, anotadas em caderno de campo, fica evidente o controle corporal na saída dos alunos da sala de aula para o refeitório. Nessa passagem, em que os alunos são obrigados a permanecer alinhados em suas filas, sem desobedecer às ações impostas pelas professoras, podemos perceber o papel desse corpo como objeto e alvo de poder. Um corpo que "se manipula, se modela, se treina, que obedece, responde, se torna hábil ou cujas forças se multiplicam" (FOUCAULT, 2015, p.117). Um corpo marcado pelas ações daqueles que, de alguma forma, detêm o poder.

Quando Foucault (2015) se refere à escola como sendo o espaço onde o poder disciplinar produz saber, ele nos transmite a ideia de uma instituição marcada por seu poder disciplinador e hierárquico, 
poder esse que emerge dos corpos dóceis e submissos a esse sistema controlador, que busca a todo o momento modelar os comportamentos e as ações dos sujeitos que se encontram sob seu domínio.

Esse controle minucioso sobre os corpos pode ser traduzido pela constante intervenção da escola nas ações dos alunos e pela busca de legitimar o poder de punição (FOUCAULT, 2015), sendo esse mais um dos aspectos que nos chamou a atenção durante a pesquisa, ou seja, a relação medo/ punição que se desenvolve por meio dessas relações de poder.

Embora os alunos procurassem viver o momento do recreio de forma intensa e brincar de tudo aquilo que tivessem vontade, o binômio medo/punição era bastante visível. "Constantemente, durante as observações, fomos indagadas sobre o que fazíamos ali e se anotaríamos o nome de quem estava fazendo algo de errado". As crianças continuamente buscavam fugir dos olhares dos inspetores e também dos pesquisadores. Observemos outro episódio descrito no diário de campo:

\begin{abstract}
Quatro alunos brincam de golpes de lutas, se agarram e tentam derrubar um ao outro. Eles se encostam numa parede e se organizam em duplas, eles chamam de time e o objetivo é fazer com que os adversários caiam. Eles mudam a dupla (time) a cada rodada. Quando um cai o outro não pode ajudar a se levantar, se os dois componentes de um mesmo time caírem a rodada acaba e trocam-se os times. Quando o inspetor aparece eles começam a gritar: Vamos parar! Vamos parar! Mas quando o inspetor se afasta, um dos alunos grita: Bora continuar! (EPISÓDIO DO CADERNO DE CAMPO).
\end{abstract}

A realização da punição está intimamente relacionada com a urgência de se manter controle sobre os corpos. A escola se mostra por meio de um aspecto controlador em que a disciplina se torna um fator fundamental e dominante no processo educacional. As crianças percebem esse poder exercido e sabem que estão sendo vigiadas, observadas e monitoradas o tempo todo. 0 constante controle exercido sobre essas crianças e a busca pela docilização de seus corpos podem ser compreendidas em Foucault (2015) e observadas nas narrativas do fato:

Dois meninos brincam de escalar a parede e segurar nas grades da janela com o objetivo de atravessarem de um lado para o outro sem caírem. Os alunos sabem que não podem subir e vigiam a presença do inspetor. Mas logo, percebem que também estão sendo observados por uma câmera, o que acaba dificultando o término da brincadeira (EPISÓDIO DO CADERNO DE CAMPO).

Podemos perceber que os alunos apresentam conhecimento sobre esse poder controlador manifestado pela escola e, mesmo assim, criam seus meios para burlar (CERTEAU, 2009) o sistema imposto. Porém, essa hierarquia e também as manifestações de poder não são apenas observadas entre os alunos e os funcionários da escola, mas até mesmo entre os próprios alunos é visível a ocorrência dessas manifestações. Foucault (2015) menciona que tais práticas são justificadas pelo ato da própria escola hierarquizar os alunos e o saber em séries e graus, reforçando essas diferenças:

\footnotetext{
Um aluno saiu da sala com uma bola e logo se formou um grupo de meninos na quadra, em poucos minutos se dividiram e começaram a jogar. Um menino do segundo segmento chegou gritando: Chegaram os maiores! Chegaram os maiores! Então, o jogo foi parado e eles tiveram que formar um novo time incluindo os maiores (EPISÓDIO DO CADERNO DE CAMPO).
}

O uso constante das estratégias e das táticas (CERTEAU, 2009) pelos alunos também demonstra um cenário marcado pelas manifestações de poder, onde cada educando busca satisfazer a todo tempo seus desejos e necessidades, na intenção de romper com esse contexto de sujeição e obediência às regras estabelecidas.

Outras relações de poder também emergiram em meio ao cotidiano investigado: as questões de gênero e sexualidade. Percebemos que os meninos e as meninas, ao praticarem o espaço do recreio, manifestavam suas brincadeiras marcadas pelos papéis socioculturais em que estavam imersos. Os comportamentos feminino e masculino se apresentavam de formas distintas e acabavam assumindo 
expectativas diferenciadas, sob a influência da sociedade, que apresenta normas de condutas apropriadas para cada gênero.

Para Felipe (2000), o contato corporal entre as crianças, muitas vezes, passa a ser "disfarçado", devido à existência de uma censura que "coíbe" o contato físico e que, de alguma forma, tenta ocultar as questões da sexualidade.

Ao longo do tempo, os comportamentos ideais para homens e mulheres foram sendo modelados, normalizados (FOUCAULT, 2015) e acabaram se tornando referências, normas, para a sociedade e, em decorrência, para as aprendizagens infantis sobre os papéis ocupados por meninos e meninas. Essas crianças já chegam à escola com essa visão de diferença para os papéis sociais a serem desempenhados, que são transmitidos por meio de suas relações sociais e familiares (PENNA, 2015).

Louro (2008, pp. 80-81) destaca que "a escola não apenas reproduz ou reflete as concepções de gênero e sexualidade que circulam na sociedade, mas que ela própria as produz". Muitas vezes estabelece padrões de comportamento e hierarquias sociais entre meninas e meninos. Vejamos a seguir: "um grupo de alunos chega na quadra para jogarem futsal, mas entre eles há a presença de apenas uma menina, pois as outras estão entretidas com brincadeiras como: Brincar de casinha, boneca ou se fingirem de princesas..." (EPISÓDIO DO CADERNO DE CAMPO).

A divisão das brincadeiras por gêneros, às vezes, surgia ao nosso redor, deixando transparecer concepções de mundo das crianças em um cotidiano que se apresenta de maneira inusitada e complexa, permitindo aos fios que se enredam ao contexto sociocultural emergirem sutilmente. Souza e Altmann (1999) revelam que

\begin{abstract}
na aparência das diferenças biológicas entre os sexos ocultaram-se relações de poder - marcadas pela dominação masculina - que mantiveram a separação e a hierarquização entre homens e mulheres, mesmo após a criação da escola mista, nas primeiras décadas deste século. Buscou-se manter a simbologia da mulher como um ser dotado de fragilidade e emoções, e do homem como força e razão, por meio das normas, dos objetos, do espaço físico e das técnicas do corpo e dos conteúdos de ensino, fossem eles a ginástica, os jogos ou - e sobretudo - os esportes (SOUZA; ALTMANN, 1999, p. 57).
\end{abstract}

Na passagem supracitada, é possível perceber e compreender essa construção social e cultural das questões relacionadas ao gênero e, essa "supremacia" do ser masculino em relação ao ser feminino. À mulher, foi destinado o papel de um ser doce e frágil, já o homem foi marcado como detentor da força e da razão.

A dança e a arte, e também os jogos de pouco contato corporal, sempre foram relacionados à mulher; já os esportes violentos e que exigiam bastante esforço físico se restringiam aos homens (SOUZA; ALTMANN, 1999). No que tange às práticas corporais produzidas por meninos e meninas, essa diferença, ainda hoje, é bastante clara e facilmente percebida na escola. Muitas vezes, as brincadeiras são divididas e rotuladas como sendo adequadas para meninos ou meninas, reforçando as identidades e as diferenças.

Para Wenetz, Stigger e Meyer (2013, p. 119), "é dessa forma que o recreio se constitui também em um espaço de aprendizagem social, no qual as normas e as regras acerca de diferentes aspectos da cultura dos estudantes" são apreendidas por meio da sociabilidade que emerge desse espaço construído no cotidiano da escola.

Assim como as questões de gênero são inscritas nos corpos, a sexualidade também faz parte de uma construção social que marca as relações dos sujeitos e está presente no ambiente escolar. "A 
sexualidade está na escola, porque ela faz parte dos sujeitos, ela não é algo que possa ser desligado ou algo do qual alguém possa se "despir" (LOURO, 2008, p. 81). A autora ainda salienta que

inscrevemos no corpo marcas de identidade e, consequentemente, de diferenciação. Treinamos nossos sentidos para perceber e decodificar essas marcas e aprendemos a classificar os sujeitos pelas formas como eles se apresentam corporalmente, pelos comportamentos e gestos que empregam e pelas várias formas com que se expressam (LOURO, 2001, P.15).

A escola, portanto, tende a conferir e a inscrever nos corpos de seus alunos as marcas de identidade consideradas adequadas para cada gênero, diferenciando-os por meio de grupos sociais, ou seja, mantendo-os em uma zona de conforto e atribuindo-lhes os papéis indicados para cada gênero "Os gêneros se produzem, portanto, nas e pelas relações de poder" (LOURO, 2008, p. 41).

Contudo, podemos perceber que o recreio, em momentos distintos, apresenta fissuras em que as crianças conseguem manifestar e criar autonomamente as suas possibilidades de ação, sem que sejam modeladas, controladas ou direcionadas pela figura do professor ou qualquer adulto no âmbito escolar. Sejam quais forem essas ações - comer, brincar ou conversar - elas buscam fazer tudo isso de forma intensa, aproveitando cada minuto desse espaço de tempo precioso. As ações dos alunos revelam tal comportamento: "Alguns alunos do quarto ano já saíram correndo com uma bola na mão e nem passaram pelo refeitório para lanchar. Um desses alunos me disse que tinha que escolher entre comer ou brincar porque o tempo era muito curto" (EPISÓDIO DO CADERNO DE CAMPO).

Por diversas vezes nos espantávamos com a dinâmica estabelecida pelos alunos e as escolhas que faziam, optando pelo brincar ao invés de lanchar, conforme explicitado no episódio supracitado. Podemos perceber que as crianças sabem que o tempo do recreio também deve ser vivenciado e utilizado para outros fins, porém o brincar se torna a ação mais importante nesse momento. De acordo com a autora Guzzoni (1998, p.42), "as interpretações e os significados que as crianças possuem do recreio variam de acordo com múltiplas influências e podem se modificar também de acordo com a experiência vivenciada".

Wenetz, Stigger e Meyer (2013, p. 117) deixam esse espaço - recreio - ainda mais complexo, pois mencionam que "o recreio tem vários sentidos (estudantes, funcionários, professores e a direção da escola atribuem sentidos diferentes ao recreio) e também uma rotina própria não vinculada apenas ao espaço, ao tempo e às atividades que nele ocorrem". Ao considerar o exposto, vamos perceber que essas concepções se cruzam e, às vezes, ocasionam tensões e conflitos: se para as crianças o recreio serve para brincar, na perspectiva da escola (docentes e funcionários) serve para merendar.

Retomando a perspectiva das crianças, é por meio do brincar que elas se reapropriam dos produtos que lhes chegam, consumindo de modo diferente as práticas socioculturais. Cabe ressaltar que as crianças não se limitam a consumir apenas o que é oferecido como pronto e acabado por uma produção racionalizada e que se mostra por meio de operações próprias, mas sim um consumo astucioso, que se desenvolve por intermédio de suas próprias regras e 'maneiras de fazer', conforme destaca Certeau (2009):

A uma produção racionalizada, expansionista além de centralizada, barulhenta e espetacular, corresponde outra produção, qualificada de 'consumo': esta é astuciosa, é dispersa, mas ao mesmo tempo ela se insinua ubiquamente, silenciosa e quase invisível, pois não se faz notar com produtos próprios, mas nas maneiras de empregar os produtos impostos por uma ordem econômica dominante. (CERTEAU, 2009, p. 39).

Certeau (2009) valoriza aquilo que ele chama de arte de fazer, momento em que as crianças deixam de lado os modelos prontos e acabados impostos por uma economia dominante e se permitem 
criar e reinventar. É a partir desse novo, que resulta da união de diversos elementos culturais, que o autor vê surgir o termo bricolagem.

A bricolagem permite que as circunstâncias recebam formas distintas e se adaptem à realidade que necessita ser vivida naquele momento. As crianças buscam modelar tudo aquilo que precisa ser reconstruído, para que suas ações sejam realizadas. Observemos o seguinte episódio:

\footnotetext{
O dia está chuvoso e a única quadra da escola ocupada. Alguns alunos querem jogar futsal, mas o ambiente do pátio não está favorável para que isso aconteça. Porém, logo dão um jeito. Os tênis se transformam nas traves do gol e a bola é feita por papel, sacola plástica e fita. Logo, a brincadeira se desenvolve e as crianças se divertem (EPISÓDIO DO CADERNO DE CAMPO).
}

Na bricolagem, o conhecimento é transitório e está sempre em processo (NEIRA; LIPPI, 2012). Os usuários operam de modo que suas ações não se entreguem à passividade e à disciplina, ou seja, a uma racionalidade que hoje domina (CERTEAU, 2009). As crianças estão a todo tempo prontas para burlar, para fugir da realidade imposta e se aventurarem em suas próprias criatividades e maneiras de fazer.

Assim, os educandos se apropriam do pátio escolar, transformando-o em um lugar praticado. A criança passa a criar e a inventar esse espaço do cotidiano, buscando escapar do lugar que lhe é atribuído, e é por meio das práticas que elas vão desenhando esse espaço de ações. Segundo Certeau (2009), a prática vai sendo realizada dia a dia por meio dos comportamentos que insinuam essa cultura do movimento, no qual as crianças estão inseridas. Para ele "'prático'vem a ser aquilo que é decisivo para a identidade de um usuário ou de um grupo, na medida em que essa identidade lhe permite assumir o seu lugar na rede de relações sociais inscritas no ambiente" (CERTEAU, 2009, p.40).

\section{UM SER QUE CRIA, RECRIA E SE REINVENTA}

Talvez seja difícil dizer o motivo pelo qual decidimos mergulhar e investigar o cotidiano das crianças na escola, mais especificamente durante o recreio escolar, porém já não é demais dizer que esse tema nos fascinou e ampliou nosso conhecimento e maneira como percebemos o mundo e toda a complexidade que dele emerge. Se inicialmente passávamos por esse espaço (recreio) sem perceber as práticas que ali são produzidas, posteriormente nos deixávamos marcar pelas brincadeiras e ações dos praticantes, que fabricam outras formas de estar no mundo. Parafraseando Larrosa (2002), a verdadeira experiência é aquela capaz de nos tocar e não simplesmente aquela que passa despercebida aos nossos olhos sem que possamos nos apropriar das marcas por ela deixadas.

Num primeiro momento, quando o convite foi feito e o tema proposto por nosso orientador, sentimos um pouco de medo e estranhamento, pois o que teria de interessante e útil em estudar o dia a dia, e tudo aquilo que se repete dia após dia? Porém, com o decorrer da pesquisa, percebemos que o cotidiano pode, sim, ser um interessante objeto de estudo e fonte de saber.

Adentrar no mundo daquelas crianças possibilitou-nos ter um novo sentimento pelo mundo (ALVES, 2003). Abrimos os olhos, os ouvidos, ampliamos nosso olfato e intuição, para compreendermos um pouco mais sobre o universo dos alunos e sobre tudo aquilo que estavam dispostos a realizar. Foi preciso apenas dar a eles um espaço, para percebermos o quanto as crianças são capazes de criar e reinventar, de modo que suas ações e desejos se realizassem.

No mundo dessas crianças, um simples objeto era capaz de tornar-se o brinquedo mais fabuloso e desafiador, conforme mencionamos na passagem em que os alunos se penduram nas grades da janela para atravessar de um lado para o outro; logo, um artefato criado para controlar se transforma 
em um artefato do brincar. Assim, ao mesmo tempo em que as crianças desafiam o poder, conforme os dados apresentados no caderno de campo, elas recriam uma nova função para aquele simples objeto, que passa a fazer parte do universo daqueles discentes.

Mesmo que a escola, a todo o momento, formulasse padrões de comportamento para os corpos, ela não conseguia tirar dos alunos a criatividade em burlar o sistema e as regras exigidas. Os alunos manifestavam em suas ações uma engenhosidade única que lhes permitia construir o espaço em que estavam imersos.

Embora achássemos que o cotidiano do recreio escolar não nos traria muitas coisas novas e interessantes, percebemos que há sempre algo diferente a ser descoberto e vivido. Não precisava de muitas coisas para que os brinquedos se desenvolvessem e as brincadeiras surgissem, fazendo com que os alunos se deliciassem naquele reduzido espaço de tempo.

Outro aprendizado com as crianças emerge da noção de cotidiano e se aproxima do que Certeau (2009) nos apresenta: a rotina que se reproduz cotidianamente sempre se desenvolve de maneira diversa, singular e original. Um exemplo que evidencia o aprendizado mencionado salta aos olhos quando acompanhávamos, após o sinal do recreio, as crianças desesperadas comparecendo no espaço destinado a elas e elaborando a cada dia novas situações e brinquedos.

Mas, como diria Nilda Alves (20030, é necessário "mergulhar" no cotidiano, pois só assim iremos nos apropriar das práticas produzidas nesse espaçotempo de estudos, construindo novos conhecimentos e maneiras de enxergar o mundo, levando assim, olhares diferenciados para aqueles que nunca ousaram enxergar o cotidiano de outra forma.

\section{CONSIDERAÇÕES FINAIS}

O recreio escolar, de modo geral, é entendido como um local onde as crianças brincam, na intenção de descansar das horas exaustivas de trabalho em sala de aula e, em decorrência, um espaço destinado para que os docentes e alunos possam lanchar, o que o caracteriza com uma configuração utilitarista.

Tal ótica se distancia da percepção desenvolvida neste estudo, que percebe o referido espaço como um lócus de produção de conhecimentos. Por diversas vezes, esse espaço passa por despercebido e é encarado como um espaço dedicado apenas à diversão.

Tendo em vista os aspectos observados, foi possível concluir que, embora o recreio escolar seja concebido de tal forma e ocorra em um ambiente institucionalizado, o seu espaço pode ser pensado na perspectiva da construção de diversos saberes, pois ainda que a escola busque conferir controle aos corpos, as possibilidades de criação e reinvenção de movimentos podem ser claramente percebidas nesse local.

Portanto, esse aspecto controlador demonstrado pela escola não inviabiliza o desenvolvimento de estratégias e táticas pelos sujeitospraticantes no espaço do recreio. É nessa rede de relações do cotidiano que os alunos vão tecendo significados para todas as ações por eles praticadas.

Embora, muitas vezes, as ações das crianças esbarrassem em questões como gênero e sexualidade ou até mesmo no domínio que a escola desempenha sobre os corpos, a criatividade era indiciariamente evidenciada. Os alunos reinventavam todo aquele espaço, ressignificando corpos e objetos, de acordo com suas demandas e necessidades. 
Desse modo, cabe aos educadores darem maior atenção a esse espaço, pois, por meio dele, as crianças também ampliam seus conhecimentos e desenvolvem tanto os aspectos motores quanto os cognitivos, sociais, políticos e culturais, ampliando assim suas relações com o mundo vivido.

Por fim, por meio desse espaço, poderemos apreender um pouco melhor a forma como essas crianças percebem o mundo em que estão inseridas e, assim, compreenderemos um pouco mais sobre esse complexo objeto de estudo, que é o cotidiano do recreio escolar.

\section{REFERÊNCIAS}

ALVES, N. Sobre movimentos das pesquisas nos/dos/com os cotidianos. Revista Teias. Rio de Janeiro, v. 4, n. 7-8, p. 1-8, jan/dez. 2003.

ALVES, L. R. G.; PRETTO, N. Escola: espaço para a produção de conhecimento. Comunicação \& Educação, v. 6, n. 16, 2008.

BENVEGNÚ, M. M. Rádio escolar. recreio sintonizado. 2012. 40 f. Monografia (Curso de Especialização em Mídias na Educação) - Centro Interdisciplinar de Novas Tecnologias na Educação. Universidade Federal do Rio Grande do Sul. Porto Alegre, 2012.

CAMPOS, J.; COSTA, S. Animação de recreios: projeto de intervenção em contexto escolar. Interacções, v. 10, n. 29, 2014.

CERTEAU, M. de. A invenção do cotidiano. 1. Artes de fazer. 16. ed. Petrópolis: Vozes, 2009.

A invenção do cotidiano. 2. Morar, cozinhar. 9. ed. Petrópolis: Vozes, 2009.

CRUZ, T.M; CARVALHO, M. P. Jogos de gênero: o recreio numa escola de ensino fundamental. Cadernos pagu, v. 26, p. 113-143, 2006.

DE CASTRO LIMA, M. E. C; GERALDI, C. M. G; GERALDI, J. W. O trabalho com narrativas na investigação em educação. Educação em Revista. Belo Horizonte, v.31, n.01, p.17- 44, Janeiro-Março, 2015.

FELIPE, Jane. Infância, gênero e sexualidade. Educação \& Realidade, v. 25, n. 1, 2000.

FERRAÇO, C. E.Pesquisa com o cotidiano. Educação \& Sociedade. Campinas, v. 28, n. 98, p. 73-95, 2007.

FOUCAULT, M. Vigiar e punir: nascimento da prisão. 41. ed. Petrópolis: Vozes, 2015.

GEERTZ, C. A interpretação das culturas. 1.ed. 14 reimpressão. Rio de Janeiro: LTC, 2013.

GIL, A.C. Como elaborar projetos de pesquisa. 5. ed. São Paulo: Atlas, 2010.

GUZZONI, C. V. Dimensão simbólica do recreio na escola de primeiro grau: uma análise a partir das práticas cotidianas. 1998. 134f. Dissertação (Mestrado em Educação Física) - Faculdade de Educação Física, Universidade Estadual de Campinas, Campinas, 1998.

LARROSA, J. Notas sobre a experiência e o saber de experiência. Revista brasileira de educação, v. 19, n. 1, 2002. 
LOURO, G.L. Gênero, sexualidade e educação. Uma perspectiva pós-estruturalista. 10. ed. Petrópolis: Vozes, 2008.

LOURO, G. L. (org.) O corpo educado: pedagogias da sexualidade. Belo Horizonte: Autêntica, 2001.

MATOS, Andreia; PETRICA, João. O recreio escolar: Observação dos comportamentos de crianças do $1^{\circ}$ ciclo. Revista de Ciencias del Deporte, v. 11, n. 4, p. 19-20, 2015.

NEIRA, M. G.; LIPPI, B. G. Tecendo a colcha de retalhos: a bricolagem como alternativa para a pesquisa educacional. Educação \& Realidade, v. 37, n. 2, p. 607-625, 2012.

NEUENFELD, D. J. Recreio Escolar: 0 que acontece longe dos olhos dos Professores? Revista da Educação Física/UEM, v. 14, n. 1, p. 37-45, 2008.

NÓVOA, A. Formação de professores e profissão docente. In: Nóvoa, A. (org). Os professores e sua formação. Lisboa: Publicações Dom Quixote; 1997. p.15-33.

OLIVEIRA, I. B. 0 currículo como criação cotidiana. 1. ed. Petrópolis: DP et Alii, 2012.

OLIVEIRA, I. B; ALVES, N. (orgs).Pesquisa no/do cotidiano das escolas: sobre redes de saberes.1. ed. Rio de Janeiro: DP\&A, 2001.

PAIS, J. M. Vida cotidiana: enigmas e revelações. 1. ed. São Paulo: Cortez, 2003.

PENNA, Cleuza. Brincadeiras no recreio: uma reflexão sobre as relações de gênero e sexualidade. 1. ed. Curitiba: Appris, 2015.

SILVA, K. F. da; LYRIO, K. A.; MARTINS, N. S. Michel de Certeau e a educação. Pró-Discente: Caderno de Prod. Acad.-Cient. Progr. Pós-Grad. Educ., Vitória-ES, v. 17, n. 2, jul./dez. 2011

SOUSA, E. S.; ALTMANN, H. Meninos e meninas: expectativas corporais e implicações na educação física escolar. Cadernos Cedes, ano XIX, n. 48, 1999.

ZABALZA, M. A. Diários de aula: um instrumento de pesquisa e desenvolvimento profissional. Porto Alegre: Artmed, 2004.

WENETZ, I.; STIGGER, M. P.; MEYER, D. E. As (des) construções de gênero e sexualidade no recreio escolar. Revista Brasileira de Educação Física e Esporte, v. 27, n. 1, p. 117-128, 2013. 